\title{
Feline-Human Zoonosis Transmission in North Africa: A Systematic Review
}

\author{
Breck Peterson and Amber N. Barnes
}

\begin{abstract}
Throughout human history, domestic animal species have represented a unique zoonotic disease risk for the transmission of pathogens ranging from viral, bacterial, parasitic, and fungal. In North Africa, cats have a particularly long record and occupy a specialized niche within many communities. This systematic review was conducted to analyze the current and historical literature documenting the breadth and variety of zoonoses in North Africa, specifically relating to the domesticated feline. Multiple electronic databases were searched on January 16, 2019, for published reports on feline zoonoses in North Africa. A total of 76 studies met the inclusion criteria for a full assessment. Articles selected for the review ranged in publication dates from 1939 to 2019 and included a case study, cross-sectional surveys, genomic analyses, and a book chapter. The most commonly studied pathogen was Toxoplasma gondii $(n=17)$ followed by a variety of helminths $(n=10)$. Of the countries in the target region, most publications were of studies conducted in Egypt $(n=53)$ followed by Tunisia $(n=12)$, Algeria $(n=11)$, Morocco $(n=5)$, and Libya $(n=3)$. The results of this review identify a variety of viral, bacterial, fungal, and parasitic zoonotic diseases associated with cats in North Africa, ranging from historically endemic diseases in both human and animal populations in the region, to emerging infections with recent confirmatory diagnoses. This review describes reported feline zoonoses in North Africa and provides recommendations for their prevention and control. In addition to vaccination campaigns for domesticated felines and postexposure prophylaxis for humans, prompt veterinary and medical care of exposure risks and subsequent infections are essential in limiting the zoonotic disease burden in North African communities of humans and cats.
\end{abstract}

Keywords: zoonotic disease, North Africa, One Health, veterinary, feline, global health

\section{Introduction}

A S LONG AS ANIMALS have been living alongside humans, domesticated species have represented a unique risk to humans in the transmission of pathogens ranging from viral, bacterial, parasitic, and fungal. Zoonoses are infectious diseases that spread between animals and humans, and account for nearly $60 \%$ of all infectious disease in humans (Salyer et al. 2017). Losses resulting from zoonotic disease span animal and human health, productivity and income for households and communities, and costs associated with human and veterinary treatment (Torgerson and Macpherson 2011). In low-resource countries, zoonotic disease accounts for almost half of all human deaths and make up a significant proportion of disability-adjusted life-years within populations (Torgerson and Macpherson 2011, Salyer et al. 2017). Quantifying the global burden of zoonoses is difficult, particularly in North Africa. However, this region represents a substantial portion of the total zoonotic cases of helminthiasis, leishmaniasis, and leprosy (Hotez et al. 2012).

Research into zoonotic disease risks from companion animals have often focused on canines (Macpherson 2012). Yet the feline has a long history in North Africa and the Middle East, and occupies a unique niche in these communities. Complete domestication of the cat likely occurred in Egypt just 4000 years ago (Faure and Kitchener 2009). In addition to skeletal remains as archaeological evidence, depictions of cats through clay and stone figurines from Syria, Turkey, and

Department of Public Health, University of North Florida, Jacksonville, Florida, USA.

(C) Breck Peterson and Amber N. Barnes 2020; Published by Mary Ann Liebert, Inc. This Open Access article is distributed under the terms of the Creative Commons Attribution Noncommercial License (http://creativecommons.org/licenses/by-nc/4.0/) which permits any noncommercial use, distribution, and reproduction in any medium, provided the original author(s) and the source are cited. 
Israel, as well as hieroglyphs and decorated cat mummy votive offerings indicate a value of the tamed feline beyond simple rat-catchers and pelt sources (Faure and Kitchener 2009).

In the 1480s, a European traveler wrote about a shelter for street cats in Damascus, describing the phenomenon as something unique to Muslim societies (Alkhateeb Shehada 2012). The shelter had been commemorated in honor of an Islamic tradition, with popular oral versions of the story relating the birth of a litter of kittens on the Prophet Mohammed's robe, who chose to abandon his garment rather than disturb the mother cat (Alkhateeb Shehada 2012). Other histories relating the cat and the prophet are written in the canonical literature, such as the story of a woman being punished for mistreatment of a cat (Sahih al-Bukhari 3318), the disapproval of selling cats and dogs for profit (Sahih Muslim 3808), and of the prophet sanctioning an apostle to perform ablutions with water shared with a cat for drinking (Sunan Abu-Dawud 0075).

Cats are a popular pet globally and there are more domesticated felines than domesticated dogs (Vitale et al. 2019). In 2018, a quarter of all households in the United States owned at least one cat (American Veterinary Medical Association 2018). However, feline contact can put humans and other animals at risk for zoonotic disease transmission (Gerhold and Jessup 2013). For instance, cats are implicated in nearly $40 \%$ of all animal bites in the United States, with up to $80 \%$ of these bites becoming infected (Kravetz and Federman 2002). In addition to the risk of wound infection and complications such as abscess or septic arthritis, cat bites and scratches are also implicated in the spread of diseases such as rabies, cat-scratch disease (CSD), tularemia, and plague (Kravetz and Federman 2002).

In addition, feline zoonotic transmission may occur through contact with infected saliva or other excretions, contaminated vehicles like food, water, or fomites, and shared vectors or environmental exposures (Tuzio et al. 2005). These diseases and transmission routes are often associated with stray, feral, or community-owned cats, which may be less likely to receive preventive care or veterinary attention (Maia et al. 2014). The aim of this review is to identify, summarize, and describe the published literature linking felines to zoonoses in North Africa and illustrate opportunities for One Health prevention and control strategies that protect the health of humans and cats.

\section{Materials and Methods}

\section{Search strategy and selection criteria}

Electronic databases were searched on January 16, 2019, for publications on feline zoonoses in North Africa. Databases included the following: ABI/Inform Collection, Agricola, Agriculture Collection, Aquatic Sciences Collection, Biological Sciences, BioOne Complete, Biosis, CABI, Environment Complete, Environmental Science Collection, Environmental Studies and Policy, Google Scholar, Health and Medicine, MEDLINE, Nursing and Allied Health, PubMed, SAGE Journals Online, ScienceDirect, SpringerLink Journals, TOXLINE, Web of Science Core Collection, and Zoological Record. There were no date restrictions, but publications were limited to English or French due to language abilities of the reviewers. The countries of Algeria,
Egypt, Libya, Morocco, and Tunisia were selected based on the World Bank's classification of countries that comprise their Middle East and North Africa region (World Bank 2019).

Key words and search terms were developed from larger categories for the host (cat*, feline, pet*, companion animal*, kitten*, and kitty), routes of zoonotic exposure (transmission, respiratory, enteric, fecal-oral, gastrointestinal, airborne, direct contact, bite*, scratch*, wound*, saliva, contact, feces, exposure*, zoonoses, zoonosis, zoonotic, fecal, and urine), and location of interest (Algeria*, Egypt*, Libya*, Morocc*, Tunisia*, North Africa*, and MENA). These terms were used in the creation of search strings that included wildcards (*) and Boolean operators to try to capture all variations and pluralities, based upon the search principles of each database. Each database was examined for publications that contained at least one search term from each category in the title and/or abstract. Search strings included the use of OR between terms within the category and were combined using AND to make sure that the results included the correct host, a route of zoonotic exposure, and a location of interest such as the following:

1. Cat[tiab] OR cats[tiab] OR feline*[tiab] OR cats[$\mathrm{MeSH}]$ OR pet[tiab] OR Pets[MeSH] OR “companion animal',[tiab] OR kitten*[tiab] OR kitty[tiab]) AND

2. (Transmission[tiab] OR respiratory[tiab] OR enteric [tiab] OR "fecal oral" [tiab] OR gastrointestinal[tiab] OR airborne[tiab] OR “direct contact" [tiab] OR bite* [tiab] OR scratch*[tiab] OR wound*[tiab] OR saliva [tiab] OR contact*[tiab] OR feces[tiab] OR exposure* [tiab] OR zoonoses[MeSH] OR zoonotic[tiab] OR zoonosis[tiab] OR fecal[tiab] OR urine[tiab]) AND

3. (Algeria*[tiab] OR Egypt*[tiab] OR Libya*[tiab] OR Morocc*[tiab] OR Tunisia*[tiab] OR "North Africa" [tiab] OR “North African" [tiab] OR "North Africans", [tiab] OR “MENA”[tiab])

Publications were included if there was documentation of zoonoses or reverse zoonoses with feline participation in transmission within or in reference to one or more North African country. Only literature that described cases of feline-associated zoonotic transmission or in which the authors described a strong likelihood of transmission were included. Publications were excluded if the study or report referenced the zoonotic disease in only an animal or human population without discussion of confirmed zoonotic transmission or potential exposure risk from cat contact. Broad overviews and reviews were excluded if they did not specifically provide case reports or study details on feline-human zoonosis transmission.

\section{Data screening}

Guidelines from the Preferred Reporting Items for Systematic Reviews and Meta-Analyses (PRISMA) (http:// prisma-statement.org/PRISMAStatement/FlowDiagram) were followed (Moher et al. 2015). The initial search results combined from all databases $(n=2820)$ were reduced once duplicates were removed. The nonduplicate results $(n=1270)$ were then screened for categories (host, route of zoonotic exposure, and location of interest) in the title and abstract of the document. When it was not clear from reading this section 
of the publication alone, the authors erred on the side of caution and included it for the next round of screening. After exclusion from title and abstract review, 365 works remained for a full-text assessment. The authors first worked independently to read over each accessible document and then merged their findings to form a collective and unanimous decision on each article. Full-text works were excluded $(n=289)$ based on being a language other than French or English, a duplicate copy that was not discovered using citation management software, inaccessibility, no reference to zoonoses, cats, or cat/human transmission, the study location being outside of North Africa, or the article being a broad overview without specific instances of feline zoonotic transmission. In the end, the search produced 76 studies for review (Fig. 1).

\section{Results}

Articles selected for the review ranged in publication dates from 1939 to 2019 and included a case study, cross-sectional surveys, genomic analyses, and a book chapter. The most commonly studied pathogen was Toxoplasma gondii $(n=17)$ followed by various helminths $(n=10)$. Of the countries in the target region, most publications were of studies conducted in Egypt $(n=53)$ followed by Tunisia $(n=12)$, Algeria $(n=11)$, Morocco $(n=5)$, and Libya $(n=3)$ (Fig. 2). In human studies, the most common study population was patients presenting with clinical signs of infectious disease $(n=15)$, followed by pregnant women $(n=11)$. Only four studies specified children in their sample population, and only five involved populations with prior animal contact or occupational exposure to animals. In animal studies, many species beyond cats were researched, including other companion animals, livestock, poultry, and wildlife.

\section{Zoonotic diseases included in review}

The results of this review identify a variety of viral, bacterial, fungal, and parasitic zoonotic diseases associated with cats in North Africa (Table 1). Articles in this review that discussed viral infections include studies on rabies, rotavirus, avian influenza, and hepatitis E. In regard to bacterial infections, the included studies examined Bartonella spp., Brucella spp., Campylobacter spp., Coxiella burnetii, pathogenic Escherichia coli, Helicobacter pylori, Klebsiella spp., Leptospira spp., Mycobacterium avium subsp. paratuberculosis, Pasteurella spp., Rickettsia spp., Salmonella, Shigella spp., Staphylococcus spp., and Streptococcus spp. Seven studies researched fungal infections, six within the umbrella term of "dermatophytes," including Trichophyton violaceum, T. rubrum, T. tonsurans, T. mentagrophytes, T. verrucosum, T. terrestre, Microsporum canis, M. gypseum, M. audouinii, M. praecox, and Epidermophyton floccosum, and one on recently re-categorized microsporidia. Many of the included research articles studied parasitic infections in North African cats that pose a risk to humans, which were further categorized as helminths and unicellular parasites. Among the helminths studied, over 17 different genera, including cestodes, trematodes, and nematodes, are included in
FIG. 1. North African countries included in review with shading to correspond with published studies. Map created in ArcMap 10.6 (ESRI, Redlands, CA); no copyrighted material was used. ESRI, Environmental Systems Research Institute.

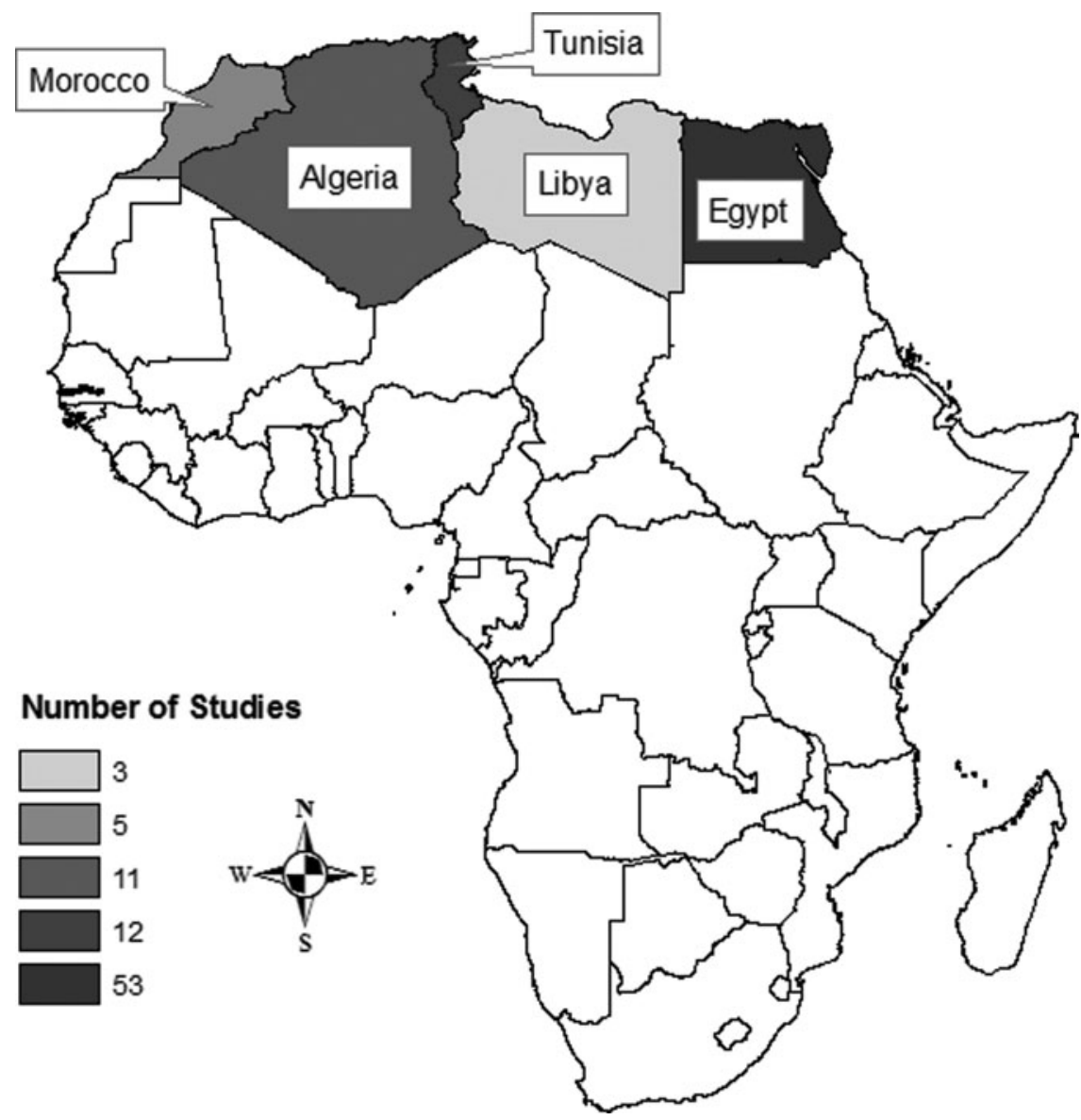


PRISMA 2009 Flow Diagram

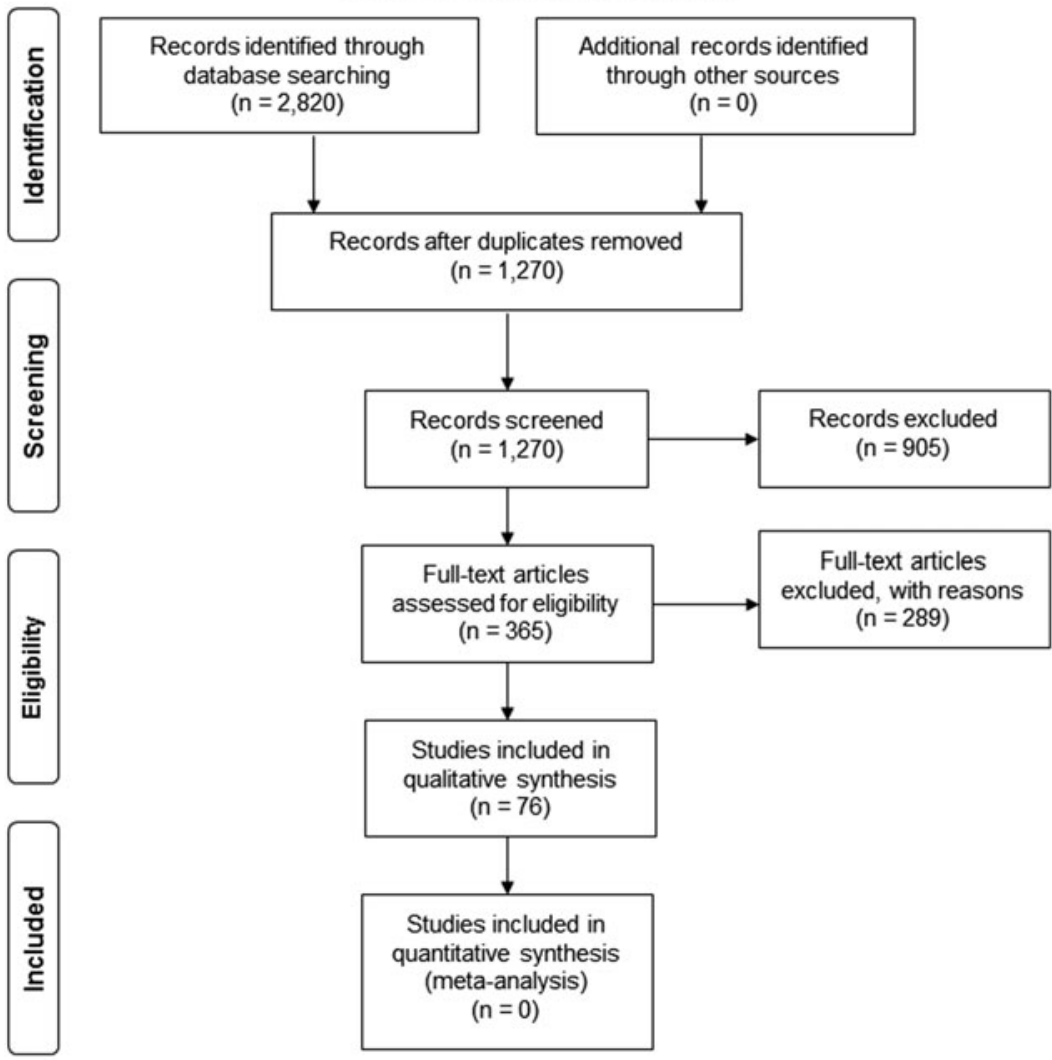

Adapted from: Moher D, Liberati A, Tetzlaff J, Altman DG, The PRISMA Group (2009). Preferred Reporting htems for Systematic Reviews and Meta-Analyses: The PRISMA Statement. PLoS Med 6(7)

this review. Additional research on unicellular parasites among the studies in this review included Cryptosporidium spp., Entamoeba histolytica, Giardia spp., Leishmania, and Toxoplasma gondii.

\section{Discussion}

North Africa is currently faced with many challenging zoonotic diseases such as echinococcosis in Tunisia, rickettsiosis in Algeria, campylobacteriosis in Egypt, rabies in Morocco, and brucellosis in Libya (Majorowski et al. 2005, Ahmed et al. 2010, Mouffok et al. 2011, Ducrotoy et al. 2015 , Helmy et al. 2017). The identified pathogens in this review range from historically endemic diseases in both human and animal populations in the region, to emerging and reemerging infections of veterinary and public health importance. Thus, a review of documented feline-associated zoonoses in these countries provides a valuable tool for comparison and retrospective determination of disease status and risk in cats and humans in North Africa.

\section{Viral infections}

Historically, rabies in this region is well recorded and recognized. In 1863, rabies was reported in 2 cats, 5 humans, and 17 dogs in Algeria by the Veterinary Surgeon Delacroix (Matter et al. 2004). In 1917, 5\% of reported animal bite victims in Algeria were of cat origin (Matter et al. 2004). In 1933, cats were responsible for 117 cases of human rabies exposure in Algeria, and from 1961 to 1980, in Tunisia, cats were responsible for $8 \%$ of treatment sought for human rabies exposure (Matter et al. 2004). Yet, animal rabies vaccination records appear primarily only available for dogs (Matter et al. 2004). Despite this, records from 1970 to 1979 in Algeria show 122 of 333 tested cats $(36.6 \%)$ were positive for rabies accounting for $10.7 \%$ of all positive animal cases during that time (Benelmouffok et al. 1982). This number increased the following year in 1980 when $48.3 \%$ of tested cats were positive for rabies (Benelmouffok et al. 1982). The researcher attributed this rise to the difficulty of capturing cats to vaccinate for rabies and that cat bites are typically serious injuries (Benelmouffok et al. 1982).

Between 1976 and 1982, in Morocco, 4.3\% of animal rabies cases were in cats (Bakkali 1985). Cats were the origin of 640 rabies postexposure treatments out of nearly 120,000 patients seeking post-exposure prophylaxis (PEP) in Egypt in 2000. In the same year, over 70,000 stray cats were culled to reduce risk of rabies transmission to humans and other animals (Matter et al. 2004). However, recent data on the number of confirmed rabies cases in humans and animals, as well as the number of those vaccinated against or treated for exposure are lacking in this region compared to the overall global numbers. The lack of current data on rabies infection in the North African region, particularly with a breakdown by animal species, does not indicate a decrease in the public health threat surrounding this pathogen, but rather a potential gap in funding and/or research priority. Many global health and veterinary organizations focus on dog-mediated rabies infection and advocate for 


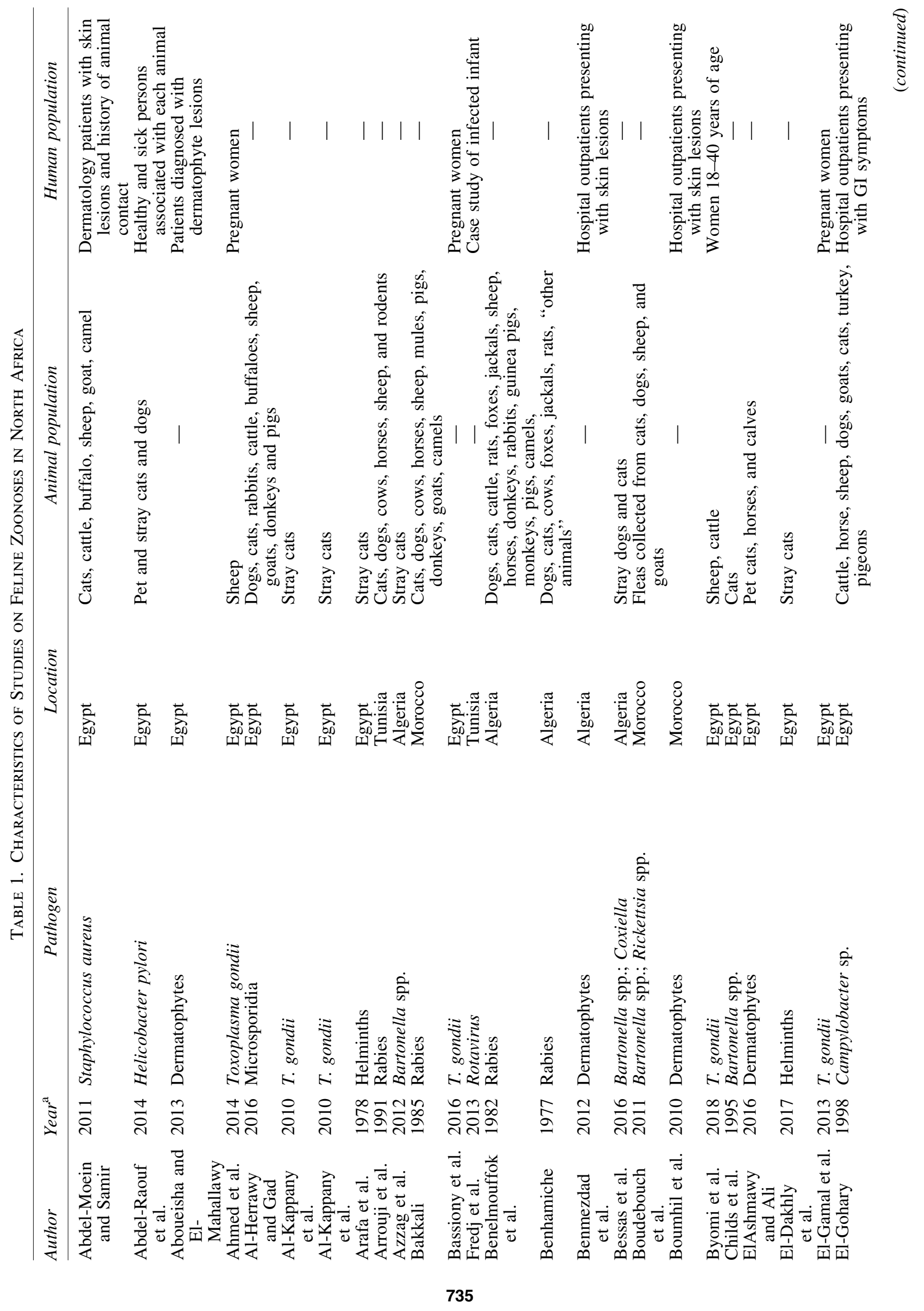




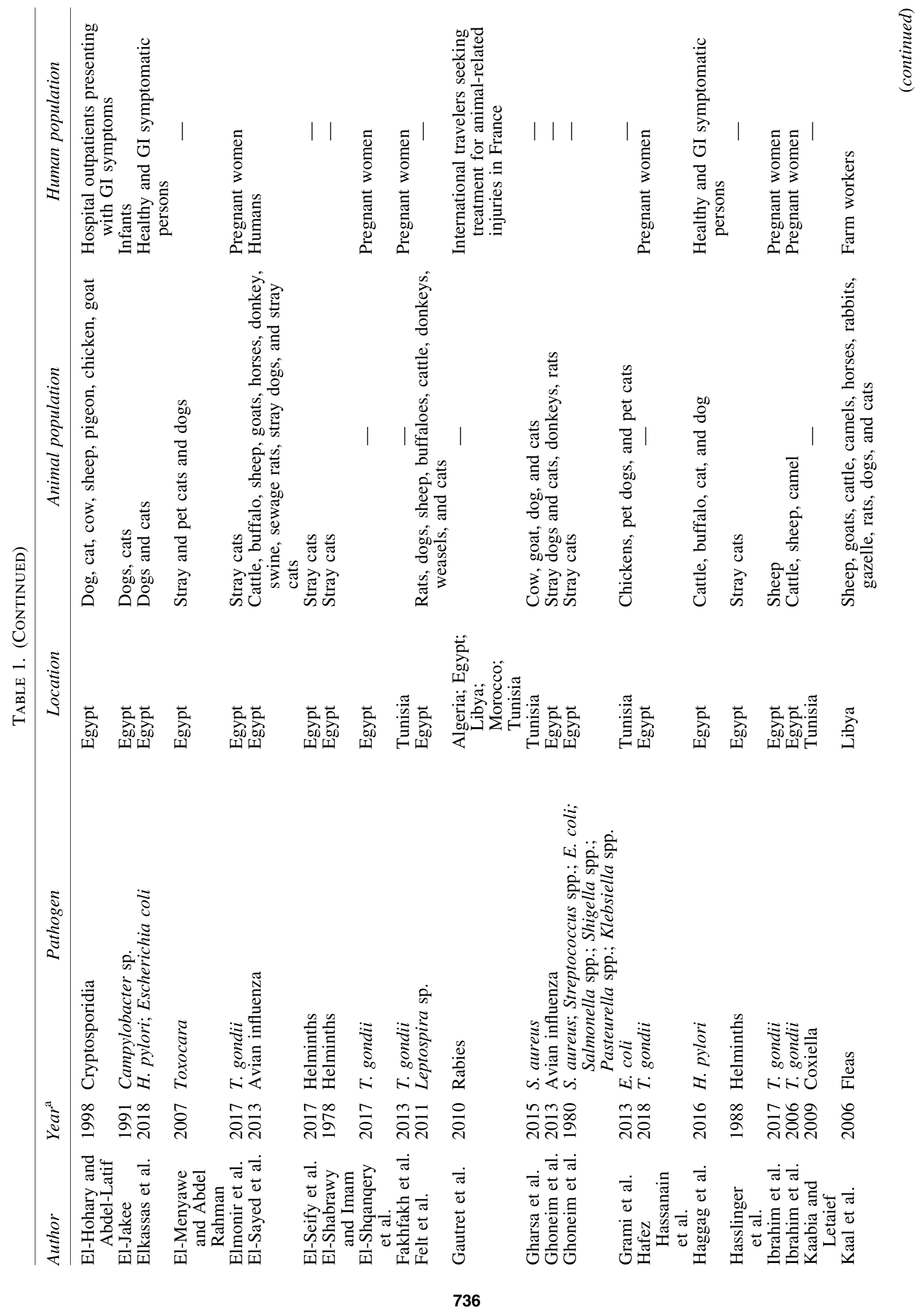




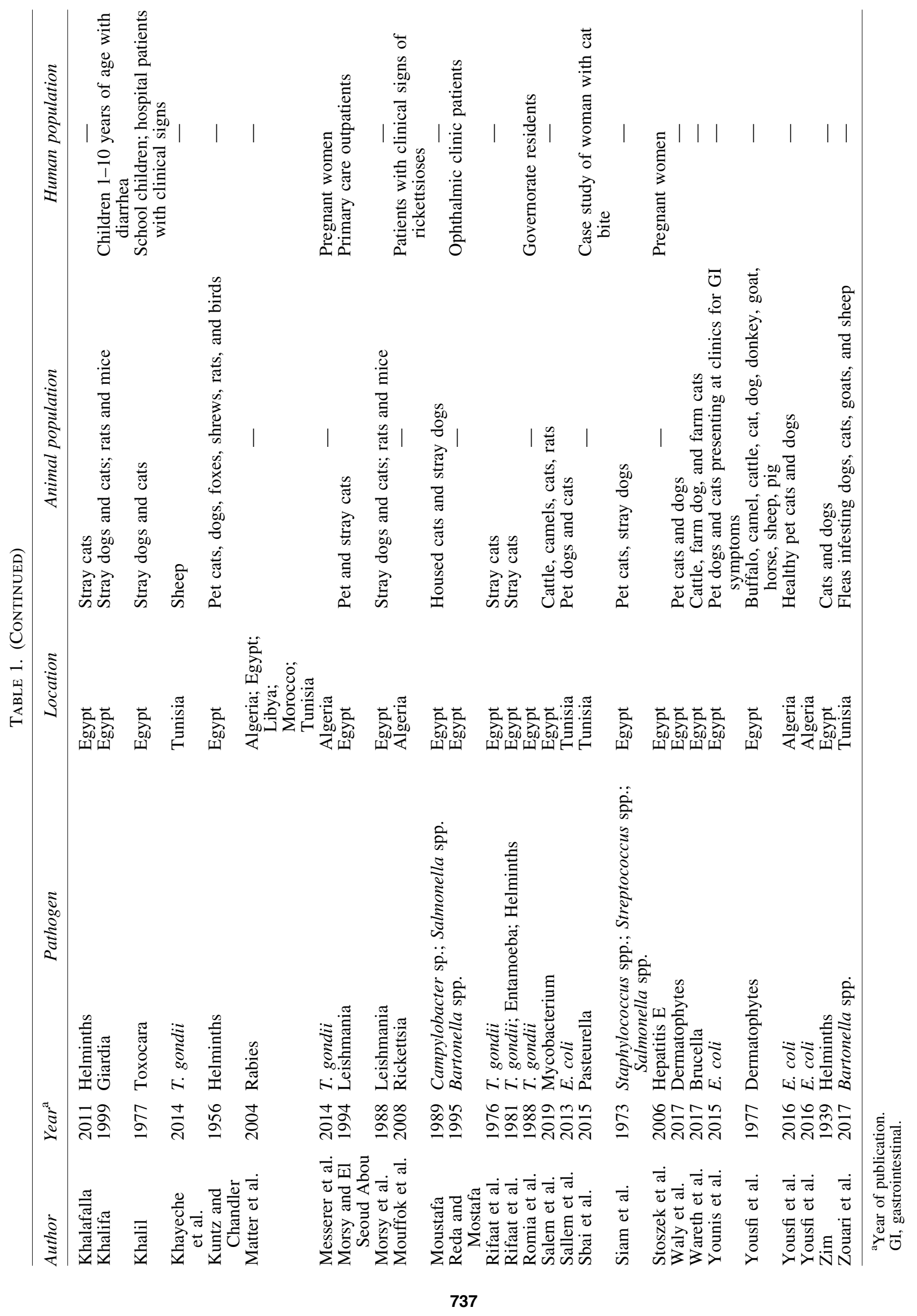


canine vaccination campaigns (World Health Organization 2019). Without data on the present state of rabies infection in North African countries, it is difficult to argue for the inclusion of felines in prevailing canine vaccination and public awareness and education campaigns.

A small number of studies were done on viral infections other than rabies, limiting direct comparisons due to inconsistencies in study methods, target populations, and outcomes measured. The two studies concerning avian influenza found disparate seroprevalence in cats ranging from $8 \%$ to $56.4 \%$ (El Sayed et al. 2013, Ghoneim et al. 2013). Stoszek et al. (2006) concluded that contact with cats was a significant risk factor associated with anti-hepatitis E virus antibody production in pregnant study participants. The single study of rotavirus in the region conducted a phylogenetic analysis on the strain found in an infected infant, which suggests a direct inter-species transmission from cat to human (Fredj et al. 2013).Viral infections represent a substantial portion of the circulating and novel infectious diseases impacting human and animal health. Viruses have the capability to quickly evolve, appear in new forms and with new properties, infect multiple species, and travel to unexpected parts of the world (Mack et al. 2015). Analysis of published literature illustrates the important role of cats as viral reservoirs and exposure risks for vulnerable populations of children, the elderly, pregnant women, and the immunocompromised.

\section{Bacterial infections}

The vector-borne bacterial disease agents researched in the review include Bartonella, Coxiella burnetii, and Rickettsia. These pathogens can be transmitted by feline fleas and ticks. The two direct studies of vector-borne pathogens (VBP) in Egyptian cats produced similar results, $17 \%$ and $19 \%$ seropositivity for Bartonella spp. (Childs et al. 1995, Azzag et al. 2012). However, they conflicted with an Algerian study that found just $1.87 \%$ of sampled cats were seropositive for VBP, including Rickettsia felis, B. henselae, and B. clarridgeia (Bessas et al. 2016). Two additional studies, in Tunisia and Morocco, tested feline fleas for the presence of VBP and found a seropositivity ranging from $33.3 \%$ for Bartonella spp. to $77.8 \%$ for at least one VBP including Rickettsia spp. and Bartonella spp. (Boudebouch et al. 2011, Zouari et al. 2017). A human study confirmed $14.5 \%$ of cases that were examined for CSD were in fact Bartonella spp. Although the authors repeatedly remarked on cat contact as a risk factor, they did not provide any data from their questionnaire to corroborate the association (Reda and Mostafa 1995). Another study of Algerian patients in a teaching hospital presenting with clinical signs of rickettsioses (spotted fevers) confirmed only 2 of the 277 potential cases were true positives and both reported frequent and recent contact with cats (Mouffok et al. 2008). Similarly, the principal risk factor for pregnant women infected with Coxiella burnetii was selfreported contact with domestic animals. Despite the fact that cat contact was implicated, their association was not specified in the study results (Kaabia and Letaief 2009).

In the studies of enteric bacterial infection rates in cats, Campylobacter spp. was found in a range from $3.3 \%$ to $10 \%$, Escherichia coli from $36.8 \%$ to $79.2 \%$, Helicobacter pylori from $28 \%$ to $33.3 \%$, Klebsiella spp. at $6.67 \%$, Leptospira spp. at $50 \%$, Mycobacterium avium subsp. paratuberculosis at $42.8 \%$, Salmonella from $2 \%$ to $12 \%$, Shigella spp. at $4 \%$,
Staphylococcus spp. from $6 \%$ to $21.3 \%$, Streptococcus spp. from 2\% to 36\%, and Pasteurella spp. at 4\% (Siam et al. 1973, Ghoneim et al. 1980, El Gohary 1998, Moustafa 1989, ElJakee et al. 1991, Abdel-Moein and Samir 2011, Felt et al. 2011, Grami et al. 2013, Sallem et al. 2013, Abdel-Raouf et al. 2014, Gharsa et al. 2015, Sbai et al. 2015, Younis et al. 2015, Haggag et al. 2016, Yousfi et al. 2016, Elkassas et al. 2018, Salem et al. 2019). However, not all of the strains that were found in cats are pathogenic to humans, and the different methodologies among the studies make direct comparisons of prevalence impractical. Brucella spp. was isolated in a cat in a single study from Egypt, which the authors postulate may have an understated impact on the reemergence and transmission of brucellosis on farms (Wareth et al. 2017).

There were limited data available on the association between cat contact in North Africa and subsequent bacterial infections in humans, as either the risk factor was mentioned, but not quantified or the prevalence in humans was not determined. One study on Helicobacter pylori did conclude that persons with cat contact had a higher probability of $H$. pylori infection than persons with contact with dogs or other animals (Abdel-Raouf et al. 2014). In addition, a case study of a woman with a cat bite was positively identified to have Pasteurella spp. in her infected wound, establishing a direct source of transmission (Sbai et al. 2015).

A substantial number of studies researched the existence of antibiotic resistance genes in samples isolated from their study populations, including cats. Resistant strains of E. coli were isolated in $7.2-36.8 \%$ of cat sampled in the relevant studies (Grami et al. 2013, Sallem et al. 2013, Younis et al. 2015, Yousfi et al. 2016). Another study found S. aureus in just $6 \%$ of cats, but noted that all isolates from cats showed penicillin resistance (Gharsa et al. 2015).

Research conducted outside of the region has found that antimicrobial resistance (AMR) is increasing within the pathogens infecting companion animals, including cats (Lloyd 2007). As demonstrated by the number of studies on AMR genes in zoonotic bacterial pathogens found infecting cats and humans in North Africa, the risk of AMR is expanding in the domestic animal population, just as in the human population (Lloyd 2007). With such risk identified, measures need to be taken to effectively prevent and control not only bacterial diseases but also the emergence of resistant genes as well.

\section{Fungal infections}

In 1977, Yousef et al. found that $18.7 \%$ of Egyptian cats were positive for at least one pathogenic fungus, while 40 years later, in 2017 , Waly et al. found that $16.7 \%$ of healthy cats were positive, suggesting remarkable stability in dermatophyte prevalence. A single study contained definitive prevalence rate numbers relating both human and feline dermatophyte infections, with animal contact a risk factor in $56.7 \%$ of positive human cases, but did not differentiate cats from other animals (Boumhil et al. 2010). Several studies commented on the rise of zoophilic species diagnosis in humans, and an increased representation in the isolates from skin lesions taken from dermatological patients (Benmezdad et al. 2012, Aboueisha and El-Mahallawy 2013).

An additional study of note, but not included in the results, is Farag et al.'s (2018) article on dermatophyte infections and associated risk factors in school children from Menoufia, 
Egypt. Pet contact was one of the leading risk factors for dermatophyte infections, which had a $1.41 \%$ overall prevalence in the study population. However, the authors did not specify what animals were included in the category of "pets" and thus the data cannot be stipulated to definitively include cat contact as a risk factor for dermatophyte infection in this population and was disqualified for inclusion in the formal review results (Farag et al. 2018).

Microsporidia, now considered fungi and not protozoa, have a transmission much more akin to enteric parasites than to dermatophyte fungal infections (Hibbett et al. 2007). Microsporidia were found in $23.1 \%$ of fecal samples from cats sampled from Egypt, with further analysis identifying them to be Enterocytozoon bieneusi and E. intestinalis species, demonstrating a common co-infection (Al-Herrawy and Gad 2016).

\section{Parasitic infections}

Helminths. Helminths are parasitic worms that are primarily intestinal, although some may reside in blood or other tissue. Taxonomically diverse, helminths encompass flatworms like trematodes or flukes, cestodes or tapeworms, and nematodes like roundworms and hookworms. Helminths re- searched for this study are transmitted to humans primarily through the soil, either through accidental ingestion of contaminated soil or by walking barefoot. While mass deworming campaigns are not uncommon in North Africa, the routine use of veterinary dewormers in the region is unknown. According to World Health Organization (WHO) data from 2016, just $11.2 \%$ of school-aged children requiring preventive chemotherapy for soil-transmitted helminths actually received it in the Eastern Mediterranean region, the WHO region, which encompasses North Africa (World Health Organization 2016).The prevalence of certain helminths in the feline population has remained surprisingly consistent according to historical data for this region. For example, Zim (1939) found a $10 \%$ prevalence of Taenia spp. in cats in 1938, while a prevalence of $9.6 \%$ was recorded in 2017 by El-Dakhly et al. (2017). It is important to note that experimental methods varied widely, as did the locations of the surveys (Table 2).

Unicellular parasites. A survey of Cryptosporidium spp. was performed in humans with gastroenteritis and animals they were in contact with, to establish the incidence of cryptosporidiosis in households and animals associated with

Table 2. Zoonotic Feline Helminth Infections in North Africa

\begin{tabular}{|c|c|c|c|c|c|}
\hline Type & Species & Location & $Y e a r^{\mathrm{a}}$ & Prevalence in cats (\%) & Author \\
\hline \multirow[t]{15}{*}{ Trematodes } & \multirow{4}{*}{ Heterophyes spp. } & Beni-Suef, Egypt & 2017 & 3.2 & El-Dakhly et al. \\
\hline & & Alexandria, Egypt & 2017 & 11.76 & El-Seify et al. \\
\hline & & Giza and Cairo, Egypt & 1978 & 1.4 & Arafa et al. \\
\hline & & Egypt & 1939 & 90 & $\mathrm{Zim}$ \\
\hline & \multirow[t]{2}{*}{ Alaria spp. } & Beni-Suef, Egypt & 2017 & 1.6 & El-Dakhly et al. \\
\hline & & Alexandria, Egypt & 2017 & 1.76 & El-Seify et al. \\
\hline & Haplorchis & Beni-Suef, Egypt & 2017 & 1.6 & El-Dakhly et al. \\
\hline & Pygidiopsis & Beni-Suef, Egypt & 2017 & 1.6 & El-Dakhly et al. \\
\hline & Proceroverum & Beni-Suef, Egypt & 2017 & 1.6 & El-Dakhly et al. \\
\hline & Prohemistomum & Beni-Suef, Egypt & 2017 & 1.6 & El-Dakhly et al. \\
\hline & Echinochasmus & Beni-Suef, Egypt & 2017 & 6.45 & El-Dakhly et al. \\
\hline & \multirow[t]{2}{*}{ Euparadistomum } & Beni-Suef, Egypt & 2017 & 4.8 & El-Dakhly et al. \\
\hline & & Giza and Cairo, Egypt & 1978 & 3.2 & Arafa et al. \\
\hline & \multirow[t]{2}{*}{ Asocotyle } & Beni-Suef, Egypt & 2017 & 1.6 & El-Dakhly et al. \\
\hline & & Giza and Cairo, Egypt & 1978 & 1.4 & Arafa et al. \\
\hline \multirow[t]{17}{*}{ Cestodes } & \multirow[t]{5}{*}{ Dipylidium caninum } & Beni-Suef, Egypt & 2017 & 62.9 & El-Dakhly et al. \\
\hline & & Alexandria, Egypt & 2017 & 18.8 & El-Seify et al. \\
\hline & & Giza and Cairo, Egypt & 1978 & 3.2 & Arafa et al. \\
\hline & & Egypt & 1939 & 50 & Zim \\
\hline & & Cairo, Egypt & 1978 & 45.5 & El-Shabrawy and Imam \\
\hline & Hymenolepis spp. & Alexandria, Egypt & 2017 & 3.52 & El-Seify et al. \\
\hline & \multirow[t]{5}{*}{ Taenia taeniaeformis } & Beni-Suef, Egypt & 2017 & 9.6 & El-Dakhly et al. \\
\hline & & Alexandria, Egypt & 2017 & 1.17 & El-Seify et al. \\
\hline & & Giza and Cairo, Egypt & 1978 & 9.2 & Arafa et al. \\
\hline & & Egypt & 1939 & 10 & Zim \\
\hline & & Cairo, Egypt & 1978 & 30.3 & El-Shabrawy and Imam \\
\hline & \multirow[t]{3}{*}{ Diplopylidium spp. } & Beni-Suef, Egypt & 2017 & $8-22.5$ & El-Dakhly et al \\
\hline & & Giza and Cairo, Egypt & 1978 & 2.7 & Arafa et al. \\
\hline & & Cairo, Egypt & 1978 & 24.2 & El-Shabrawy and Imam \\
\hline & \multirow[t]{3}{*}{ Joyeuxiella spp. } & Beni-Suef, Egypt & 2017 & 14.5 & El-Dakhly et al. \\
\hline & & Giza and Cairo, Egypt & 1978 & 0.9 & Arafa et al. \\
\hline & & Cairo, Egypt & 1978 & 31.8 & El-Shabrawy and Imam \\
\hline \multirow[t]{5}{*}{ Nematodes } & \multirow[t]{2}{*}{ Toxascaris leonina } & Beni-Suef, Egypt & 2017 & 33.8 & El-Dakhly et al. \\
\hline & & Alexandria, Egypt & 2017 & 8.23 & El-Seify et al. \\
\hline & \multirow[t]{2}{*}{ Toxocara cati } & Alexandria, Egypt & 2017 & 8.23 & El-Dakhly et al. \\
\hline & & Egypt & 1939 & 0 & Zim \\
\hline & Gnathostomata sp. & Giza and Cairo, Egypt & 1978 & 0.5 & Arafa et al. \\
\hline
\end{tabular}

\footnotetext{
${ }^{\mathrm{a}}$ Year of publication.
} 
Table 3. Studies on Feline Zoonotic Toxoplasma gondi in North Africa

\begin{tabular}{llll}
\hline Author & Location & \multicolumn{1}{c}{ Population } & Cat contact as a risk factor for human infection \\
\hline Ahmed et al. & Egypt & Pregnant women & Yes \\
Al-Kappany et al. ${ }^{\text {a }}$ & Egypt & Feral cats & N/A \\
Bassiony et al. & Egypt & Pregnant women & No \\
Byomi et al. & Egypt & Women & Yes \\
El-Gamal et al. & Egypt & Pregnant women & Yes \\
El-Shqanqery et al. & Egypt & Pregnant women & No \\
Elmonir et al. & Egypt & Pregnant women; stray cats & No \\
Fakhfakh et al. & Tunisia & Pregnant women & Yes \\
Hafez Hassanain et al. & Egypt & Pregnant women & Yes \\
Ibrahim et al. (2006) & Egypt & Pregnant women & Yes \\
Ibrahim et al. (2017) & Egypt & Pregnant women & Yes \\
Khayeche et al. & Tunisia & Sheep & Yes \\
Messerer et al. & Algeria & Pregnant women & N/A \\
Rifaat et al. (1976) & Egypt & Stray cats & N/A \\
Rifaat et al. (1981) & Egypt & Stray cats & Yes \\
Romia et al. & Egypt & Humans & \\
\hline
\end{tabular}

${ }^{a}$ While two distinct studies were published in 2010 by Al-Kappany et al., only one study presented data with seropositivity rates in cats. N/A, not available.

confirmed human cases. Overall, $6.25 \%$ of fecal samples from cats were positive for Cryptosporidium spp. oocysts (El-Hohary and Abdel-Latif 1998). While this does not exclusively imply an etiologic role between species, the high detection of oocysts in the soil establishes the relevance of animal feces as a risk factor for transmission.

Entamoeba histolytica antibodies were found in 14 of 44 stool specimens taken from stray cats, but only one had a titer of $1 / 128$ or greater to indicate a positive diagnosis at the time of sampling (Rifaat et al. 1981). While Giardia spp. was found in only $1 \%$ of stray cats in a study conducted in Egypt in 2011, the prevalence of Giardia spp. in fecal samples of stray cats was 11\% in Egypt in 1999 (Khalifa 1999, Khalafalla 2011). Within Egypt, the prevalence of Giardia spp. in school-aged children and other stray animals, including dogs, cats, rats, and mice, was also determined, but the association between positive cases across species was not explored (Khalifa 1999). Nonetheless, the author did assert that dogs and cats should be considered reservoirs of infection, while rodents may play a role in the spread of parasites (Khalifa 1999).

Leishmaniasis is a disease caused by subspecies of Leishmania pathogenic eukaryotes and causes two forms of the disease presentation (cutaneous and visceral) in humans (Morsy and el Seoud Abou 1994). The Middle East and North Africa have long been established as a region endemic to leishmaniasis (Morsy et al. 1988). The bacteria are transmitted through the vector species of phlebotomine flies (the sand fly). The sand fly may also bite other mammals, such as rodents, dogs, and cats, and thus has the potential to spread disease from animals to humans, and vice versa (Morsy and el Seoud Abou 1994). Although the main confirmed reservoir host of Leishmania species in North Africa is dogs, contemporary research has suggested the role cats have as more than just an accidental host. Evidence of Leishmania infecting cats dates back to 1912 in Algeria (Maia et al. 2008). More recently, confirmed feline cases have occurred worldwide, including the Middle East, Mediterranean, Europe, and South America (Maia and Campino 2011).

Morsy conducted a study in 1982 that instead focused on ectoparasites on rodents in Egypt, identifying positive reactions for Leishmania antibodies in $16.7 \%$ of rodents (Morsy et al. 1982). Researchers have reported human cases of cutaneous leishmaniasis since 1984, and visceral dating back to 1904 (Deperet and Boinet 1884, Nicolle and Cathoire 1905). Morsy published another study 10 years later focusing on the natural infection of Leishmania in domestic felines in Egypt (Morsy and el Seoud Abou 1994). In a survey of three regions, 2 out of 60 stray cats were found positive for Leishmania spp. The authors posit on whether these cats are accidental or reservoir hosts as they, "more or less roam the entire villages" and, unlike rats, are not "unaccepted and hated" (Morsy and el Seoud Abou 1994, p. 202).

The protozoan parasite of Toxoplasma gondii was first discovered in North Africa, so it is not a surprise that this is the pathogen with the most published studies in this review (Rouatbi et al. 2019). A disproportionate amount of T. gondii studies was located in Egypt (14 out of 17), although this trend resembles that of the studies overall (Table 3). One study, not included in the review, argued that ownership or contact with domestic felines is uncommon in Moroccan society and contact with cats is not significantly associated with T. gondii seropositivity (Ouzennou et al. 2019). Another study researched $T$. gondii in rabbits and found that the presence of cats in rabbit raising areas was significantly associated (odds ratio $=3.39$ ) with $T$. gondii infection in rabbits (Abou Elez et al. 2017). Human contact with cats was not recorded in the study by Abou Elez et al. (2017) and therefore any attempt to look for an association between cat presence and human infection was inconclusive. Thus, this study was not included in the review results either. However, studies on human $T$. gondii infection rates in North African represent a prevalence range from $1 \%$ to $82 \%$ depending upon the country and study population (Rouatbi et al. 2019). And although at least seven wild felid species in this region have the potential to transmit $T$. gondii, no published data currently exist on their role in toxoplasmosis zoonoses (Rouatbi et al. 2019).

\section{Regional trends and recommendations}

While the majority of research on this subject has been conducted in Egypt, the assumption that this nation has the 
majority of pathogens or rates of infection remains unproven. The few studies conducted in each country of this region that allows for comparison of a specific pathogen's prevalence indicate that it is more likely that the countries lacking robust research or public health veterinary surveillance have equal, if not greater, burdens compared with Egypt. In addition, this research cannot encompass the risks posed by undocumented transmission or transmission by sources apart from the domestic feline, which may add an entirely new layer to the surveillance, control, and approach of zoonoses in North Africa. Many of the feline-associated zoonotic pathogens outlined in this review can also be transmitted through contaminated food, water, or soil (i.e., Brucella spp., Giardia spp., and Toxocara spp.), by vectors (i.e., B. henselae), person to person (i.e., Cryptosporidium spp.), and by other animal hosts (i.e., Leishmania spp.).

Although the zoonotic diseases of felines in North Africa are varied and numerous, efforts to prevent and control zoonoses and reverse zoonoses in these countries are ongoing. The first line of defense is a network of veterinary public health professionals. Unfortunately, there is a disparity between access to veterinary care in North African countries, as well as between North Africa and North America. According to the World Organization of Animal Health, in 2018, Egypt had $\sim 0.64$ veterinary professionals per 1000 people, Morocco $0.074 / 1000$, and Tunisia $0.176 / 1000$. For comparison, the United States is around $0.55 / 1000$. No data were available for Algeria or Libya (Veterinarians and Veterinary ParaProfessionals 2018).

The most consistent control approach for zoonoses remains vaccination of target domestic species to prevent disease spread to humans or other species (Monath 2013). In addition to vaccination, prompt veterinary and medical care of zoonoses are essential in limiting the disease burden in North African communities. This includes programs aimed at reducing the number of feral and stray populations, which can harbor many zoonotic pathogens.

Cats managed through trap-neuter-return programs and left free roaming had higher incidence of helminth infections and lower incidence of viral and protozoan infections than cats in shelters, sanctuaries, and foster care (Andersen et al. 2018). While the study by Andersen et al. (2018) was conducted in the United States, this difference in enteric pathogens between free-roaming and confined cats could be present in North Africa as well, where the majority of felines live in the community without clear ownership. In regions where dimensions of cat ownership vary and routine veterinary care is improbable, the gap between the expected and actual roles of human and animal health care providers has allowed for a vacuity in zoonotic disease education and prevention. Historically, veterinarians have been seen as the source of information about zoonoses and their prevention for humans as well as their pets. Most physicians in a U.S. survey reported patient education on infectious disease risk should be the role of veterinarians (Grant and Olsen 1999). However, messages surrounding safe animal contact and steps to take to protect people and animals from zoonotic exposure risks should come from both human and animal health care using a collaborative voice.

While this review examined published studies of felinehuman zoonotic disease transmission within the region of North Africa, narrative accounts of feline-associated zoono- tic pathogens in singular populations of humans or animals without specific mention to transmission or transmission risk were not analyzed. Although literature not meeting the study criteria were omitted to prevent the unintentional interjection of false risk associations into the analysis, several publications were excluded that could provide information on the larger question surrounding the burden of zoonotic pathogens found within human and/or feline inhabitants of North Africa. Additional research on the prevalence of these zoonotic pathogens of public health importance within the region overall is warranted.

\section{Conclusions}

Zoonotic diseases shared between humans and felines have been, and continue to be, a public health threat that should be addressed with education and intervention strategies, which take into consideration the welfare of both species. This review has outlined several of the zoonotic feline pathogen risks that have been studied in the countries of Algeria, Egypt, Libya, Morocco, and Tunisia, as well as their most significant findings. Yet, despite the published data over the past several decades, many questions still exist on the role of felines in the spread of disease within North Africa. More research in this area is needed to create effective and comprehensive interventions for the protection of residents of this region and their feline counterparts.

\section{Acknowledgments}

The authors would like to recognize the University of North Florida Department of Public Health and the resource librarians for their support.

\section{Author Disclosure Statement}

No conflicting financial interests exist.

\section{Funding Information}

No funding received for this study.

\section{References}

Abdel-Moein KA, Samir A. Isolation of enterotoxigenic Staphylococcus aureus from pet dogs and cats: A public health implication. Vector Borne Zoonotic Dis 2011; 11:627-629.

Abdel-Raouf M, Abdel-Gleel Y, Enab A. Study on the role of pet animals for Helicobacter pylori transmission. J Am Sci 2014; 10:20-28.

Abou Elez RMM, Hassanen EAA, Tolba HMN, Elsohaby I. Seroprevalence and risk factors associated with Toxoplasma gondii infection in domestic rabbits and humans. Vet Parasitol Reg Stud Rep 2017; 8:133-137.

Aboueisha AM, El-Mahallawy H. Public health significance of dermatophytes in Ismailia and Port Said provinces, Egypt. Med Mycol J 2013; 54:123-129.

Ahmed HA, Shafik SM, Ali ME, Elghamry ST, et al. Molecular detection of Toxoplasma gondii DNA in milk and risk factors analysis of seroprevalence in pregnant women at Sharkia, Egypt. Vet World 2014; 7:594-600.

Ahmed MO, Elmeshri SE, Abuzweda AR, Blauo M, et al. Seroprevalence of brucellosis in animals and human populations in the western mountains region in Libya, December 2006-January 2008. Euro Surveill 2010; 15:19625. 
Al-Herrawy AZ, Gad MA. Microsporidial spores in fecal samples of some domesticated animals living in Giza, Egypt. Iran J Parasitol 2016; 11:195-201.

Al-Kappany YM, Rajendran C, Abu-Elwafa SA, Hilali M, et al. Genetic diversity of Toxoplasma gondii isolates in Egyptian feral cats reveals new genotypes. J Parasitol 2010; 96:11121114.

Al-Kappany YM, Rajendran C, Ferreira LR, Kwok OC, et al. High prevalence of toxoplasmosis in cats from Egypt: Isolation of viable Toxoplasma gondii, tissue distribution, and isolate designation. J Parasitol 2010; 96:1115-1119.

Alkhateeb Shehada H. Mamluks and Animals: Veterinary Medicine in Medieval Islam. Leiden, Netherlands: Brill, 2012.

American Veterinary Medical Association. AVMA pet ownership and demographics sourcebook, 2017-2018 edition. 2018. Available at https://ebusiness.avma.org/productcatalog/product .aspx? $\mathrm{ID}=1531$

Andersen LA, Levy JK, McManus CM, McGorray SP, et al. Prevalence of enteropathogens in cats with and without diarrhea in four different management models for unowned cats in the southeast United States. Vet J 2018; 236:49-55.

Arafa MS, Nasr NT, Khalifa R, Mahdi AH, et al. Cats as reservoir hosts of Toxocara and other parasites potentially transmissible to man in Egypt. Acta Parasitol Pol 1978; 25: 383-389.

Arrouji A, Lasfar ZB, Makni K. Rabies diagnostic laboratory. Institut Pasteur de Tunis. Report. Arch Inst Pasteur Tunis 1991; 68:89-95.

Azzag N, Haddad N, Durand B, Petit E, et al. Population structure of Bartonella henselae in Algerian urban stray cats. PLoS One 2012; 7:e43621.

Bakkali MM. Epidémiologie et Prophylaxie de la Rage au Maroc. In: Kuwert E, Mérieux C, Koprowski H, Bögel K, eds. Rabies in the Tropics. Berlin, Heidelberg: Springer Berlin Heidelberg, 1985;371-386.

Bassiony H, Soliman NK, El Tawab S, Eissa S, Eossa A. Seroprevalence and risk factors associated with Toxoplasma gondii infection among pregnant women in Alexandria, Egypt. J Reprod Contracept Obstet Gynecol 2016; 5:4220 4227.

Benelmouffok A, Benhassine M, Abrous M. Rabies in Algeria. Recrudescence and new epizootic aspect. Comp Immunol Microbiol Infect Dis 1982; 5:321-326.

Benhamiche B. État actuel de la rage en Algérie: Deductions Prophylactiques (Current Rabies Situation in Algeria. Deductions Relating to Prophylaxis). Thése Méd Vet Alfort 1977:35-48.

Benmezdad A, Moulahem T, Benyezzar M, Djaballah M, et al. Tinea capitis in the university hospital of Constantine (Algeria). J Mycol Med 2012; 22:354-356.

Bessas A, Leulmi H, Bitam I, Zaidi S, et al. Molecular evidence of vector-borne pathogens in dogs and cats and their ectoparasites in Algiers, Algeria. Comp Immunol Microbiol Infect Dis 2016; 45:23-28.

Boudebouch N, Sarih M, Beaucournu JC, Amarouch H, et al. Henselae and Rickettsia felis in fleas from Morocco. Ann Trop Med Parasitol 2011; 105:493-498.

Boumhil L, Hjira N, Naoui H, Zerrour A, et al. Tinea capitis in the military hospital Mohammed V (Morocco). J Mycol Med 2010; 20:97-100.

Byomi A, Zidan S, Salama A, Elsify A, et al. Public health implications of toxoplasmosis in animals and women in selected localities of Meoufia Governorate, Egypt. Assiut Vet Med J 2018; 64:12-130.
Childs JE, Olson JG, Wolf A, Cohen N, et al. Prevalence of antibodies to Rochalimaea species (cat-scratch disease agent) in cats. Vet Rec 1995; 136:519.

Deperet C, Boinet E. The boil of Gafsa in the camp of Sathonay. Méd Pharma Militaires 1884; 3:296-302.

Ducrotoy MJ, Azami HY, El Berbri I, Bouslikhane M, et al. Integrated health messaging for multiple neglected zoonoses: Approaches, challenges and opportunities in Morocco. Acta Trop 2015; 152:17-25.

El Menyawe SM, Abdel Rahman MA. A study on Toxocara species and its public health importance. Vet Med J Giz 2007; 55:219.

ElAshmawy WR, Ali ME. Identification of different dermatophytesisolated from cattle, cats and horses suffered from skin lesions. Alex J Vet Sci 2016; 49:126-132.

El-Dakhly KM, Aboshinaf AM, El-Nahass ES, Gharib AE. A preliminary study on the Helminth fauna in necropsied stray cats (Felis catus) in Beni-Suef, Egypt. J Adv Vet Res 2017; 7:87-92.

El-Gamal R, Selim M, Mohamed S, Fathy G, et al. Comparison of PCR with ELISA in diagnosis of recent toxoplasmosis in pregnant women. J Am Sci 2013; 9:824-832.

El-Gohary AH. Prospective studies on campylobacteriosis in human and animals in contact. Assiut Vet Med J 1998; 38: 192-208.

El-Hohary AH, Abdel-Latif AM. Zoonotic importance of cryptosporidiosis among some animals at Gharbia province in Egypt. Indian J Anim Sci 1998; 68:305-307.

El-Jakee J. Campylobacter jejuni associated with diarrhea of pet animals and infants. Vet Med J Giz 1991; 39:81-89.

Elkassas FA, Khaliel SA, Shawky M. Characterization of $\mathrm{He}$ licobacter pylori and Escherichia coli from stool of human and pet animals. Alex J Vet Sci 2018; 56:95-101.

Elmonir W, Harfoush MA, El-Tras WF, Kotb SA. Toxoplasmosis in stray cats and pregnant women in Egypt: Association between socio-demographic variables and high-risk practices by pregnant women. Life Sci J 2017; 14:1-5.

El-Sayed A, Prince A, Fawzy A, Abdou MI, et al. Seroprevalence of avian influenza in animals and human in Egypt. Pak J Biol Sci 2013; 16:524-529.

El-Seify MA, Aggour MG, Sultan K, Marey NM. Gastrointestinal helminths of stray cats in Alexandria, Egypt: A fecal examination survey study. Vet Parasitol Reg Stud Rep 2017; 8:104-106.

El-Shabrawy MN, Imam EA. Studies on cestodes of domestic cats in Egypt with particular reference to species belonging to genera Diplopylidium and Joyeuxiella. J Egypt Vet Med Assoc 1978; 38:19-27.

El-Shqanqery HE, Ibrahim HM, Mohamed AH, El-Sharaawy AA. Seroprevalence of Toxoplasma gondii infection and associated risk factors among asymptomatic pregnant females in Egypt. J Egypt Soc Parasitol 2017; 47:93-100.

Fakhfakh N, Kallel K, Ennigro S, Kaouech E, et al. [Risk factors for Toxoplasma gondii and immune status of pregnant women: Cause and effect?] Tunis Med 2013; 91:188-190 (Article in French).

Farag AG, Hammam MA, Ibrahem RA, Mahfouz RZ, et al. Epidemiology of dermatophyte infections among school children in Menoufia Governorate, Egypt. Mycoses 2018; 61:321-325.

Faure E, Kitchener AC. An archaeological and historical review of the relationships between felids and people. Anthrozoos 2009; 22:221-238.

Felt SA, Wasfy MO, Wael F, Samir A, et al. Cross-species surveillance of Leptospira in domestic and peri-domestic 
animals in Mahalla city, Gharbeya Governorate, Egypt. Am J Trop Med Hyg 2011; 84:420-425.

Fredj MB, Heylen E, Zeller M, Fodha I, et al. Feline origin of Rotavirus strain, Tunisia, 2008. Emerg Infect Dis 2013; 19:630.

Gautret P, Adehossi E, Soula G, Soavi MJ, et al. Rabies exposure in international travelers: Do we miss the target? Int $\mathrm{J}$ Infect Dis 2010; 14:e243-e246.

Gerhold RW, Jessup DA. Zoonotic diseases associated with free-roaming cats. Zoonoses Public Health 2013; 60:189-195.

Gharsa H, Slama KB, Gómez-Sanz E, Lozano C, et al. Molecular characterization of Staphylococcus aureus from nasal samples of healthy farm animals and pets in Tunisia. Vector Borne Zoonotic Dis 2015; 15:109-115.

Ghoneim NH, Abdel-Moein KA, Zaher HM. The potential role of animals in the epidemiology of avian influenza virus H5N1 and its public health implications. Glob Vet 2013; 11: 609-613.

Ghoneim NH, Hamed O, Abdelkarim AM. The role of stray cats in harbouring pathogens of zoonotic importance. J Egypt Vet Med Assoc 1980; 40:69-75.

Grami R, Mansour W, Dahmen S, Mehri W, et al. The bla CTXM-1 IncI1/ST3 plasmid is dominant in chickens and pets in Tunisia. J Antimicrob Chemother 2013; 68:2950-2952.

Grant S, Olsen CW. Preventing zoonotic diseases in immunocompromised persons: The role of physicians and veterinarians. Emerg Infect Dis 1999; 5:159-163.

Haggag YN, Samaha HA, Nossair MA, Al Aswally SA. Epidemiological studies on Helicobacter pylori in some animals and humans. Alex J Vet Sci 2016; 51:275-281.

Hassanain NA, Shaapan RM, Hassanain MA. Associated antenatal health risk factors with incidence of toxoplasmosis in Egyptian pregnant women. Pak J Biol Sci 2018; 21:463-468.

Hasslinger MA, Omar HM, Selim MK. Incidence of helminths in stray cats in Egypt and other Mediterranean countries [1988]. Vet Med Rev 2013; 59:76-81.

Helmy YA, El-Adawy H, Abdelwhab EM. A comprehensive review of common bacterial, parasitic and viral zoonoses at the human-animal interface in Egypt. Pathogens 2017; 6:33.

Hibbett DS, Binder M, Bischoff JF, Blackwell M, et al. A higher level phylogenetic classification of the Fungi. Mycol Res 2007; 111:509-547.

Hotez PJ, Savioli L, Fenwick A. Neglected tropical diseases of the Middle East and North Africa: Review of their prevalence, distribution, and opportunities for control. PLoS Negl Trop Dis 2012; 6:e1475.

Ibrahim HM, Mohamed AH, El-Sharaawy AA, El-Shqanqery HE. Molecular and serological prevalence of Toxoplasma gondii in pregnant women and sheep in Egypt. Asian Pac J Trop Biomed 2017; 10:996-1001.

Ibrahim MA, Ghoneim NH, Ellatef GK. Investigation of toxoplasmosis in pregnant women and slaughtered animals. Vet Med J Giz 2006; 54:215.

Kaabia N, Letaief A. Q fever in Tunisia. Pathol Biol 2009; 57 : 439-443.

Kaal JF, Baker K, Torgerson PR. Epidemiology of flea infestation of ruminants in Libya. Vet Parasitol 2006; 141:313-318.

Khalafalla RE. A survey study on gastrointestinal parasites of stray cats in northern region of Nile delta, Egypt. PLoS One 2011; 6:e20283.

Khalifa NO. Prevalence of Giardia cysts in pets, rodents, with possible implications in infantile diarrhea in Kaliobia Governorate. Vet Med J Giz 1999; 47:59-65.

Khalil HM. Toxocariasis in Egypt. J Egypt Public Health Assoc $1977 ; 52: 330$
Khayeche M, Mhadhbi M, Gharbi M, Nasfi I, et al. Detection of Toxoplasma gondii infection of sheep slaughtered in the Governorate of Sousse on the occasion of the Muslim sacrifice feast (Eid Al-Adha) and analysis of risk factors. Bull Soc Pathol Exot 2014; 107:60-63.

Kravetz JD, Federman DG. Cat-associated zoonoses. Arch Gen Intern Med 2002;162:1945-1952.

Kuntz RE, Chandler AC. Studies on Egyptian trematodes with special reference to the heterophyids of mammals. I. Adult flukes, with descriptions of Phagicola longicollis n. sp., Cynodiplostomum Namrui n. sp., and a Stephanoprora from cats. J Parasitol 1956; 42:445-459.

Lloyd DH. Reservoirs of antimicrobial resistance in pet animals. Clin Infect Dis 2007; 45(Suppl_2):S148-S152.

Mack A, Choffness ER. Emerging Viral Diseases: The One Health Connection: Workshop Summary. Washington, DC: National Academies Press, 2015.

Macpherson CN. Dogs, Zoonoses and Public Health. London, UK: CABI, 2012.

Maia C, Campino L. Can domestic cats be considered reservoir hosts of zoonotic leishmaniasis? Trends Parasitol 2011; 27: 341-344.

Maia C, Nunes M, Campino L. Importance of cats in zoonotic leishmaniasis in Portugal. Vector Borne Zoonotic Dis 2008; 8:555-560.

Maia C, Ramos C, Coimbra M, Bastos F, et al. Bacterial and protozoal agents of feline vector-borne diseases in domestic and stray cats from southern Portugal. Parasit Vectors 2014; 7:115.

Majorowski MM, Carabin H, Kilani M, Bensalah A. Echinococcosis in Tunisia: A cost analysis. Trans R Soc Trop Med Hyg 2005; 99:268-278.

Matter H, Blancou J, Benelmouffok A, Hammami S, et al. Historical perspective of rabies in Europe and the Mediterranean Basin. OIE, Paris (France), Geneva (Switzerland), 2004:185-199.

Messerer L, Bouzbid S, Gourbdji E, Mansouri R, et al. [Seroprevalence of toxoplasmosis in pregnant women in Annaba, Algeria]. Rev Epidemiol Sante Publique 2014; 62:160-165 (Article in French).

Moher D, Shamseer L, Clarke M, Ghersi D, et al. Preferred reporting items for systematic review and meta-analysis protocols (PRISMA-P) 2015 statement. Syst Rev 2015; 4:1.

Monath TP. Vaccines against diseases transmitted from animals to humans: A one health paradigm. Vaccine 2013; 31:5321-5338.

Morsy TA, el Seoud Abou SM. Natural infection in two pet cats in a house of a zoonotic cutaneous leishmaniasis patient in Imbaba area, Giza Governorate, Egypt. J Egypt Soc Parasitol 1994; 24:199-204.

Morsy TA, Michael SA, Bassili WR, Saleh MS. Studies on rodents and their zoonotic parasites, particularly leishmania, in Ismailiya Governorate, A.R. Egypt. J Egypt Soc Parasitol 1982; 12:565-585.

Morsy TA, Michael SA, Makhlouf LM. Leishmania infection sought in non human hosts in Suez Governorate, Egypt. J Egypt Soc Parasitol 1988; 18:539-545.

Mouffok N, Parola P, Raoult D. Murine typhus, Algeria. Emerg Infect Dis 2008; 14:676.

Mouffok N, Socolovschi C, Benabdellah A, Renvoise A, et al. Diagnosis of rickettsioses from eschar swab samples, Algeria. Emerg Infect Dis 2011; 17:1968.

Moustafa S. Prevalence of Campylobacter and Salmonella in cats and dogs [Egypt]. Assiut Vet Med J 1989; 22:47-53.

Nicolle C, Cathoire M. Note on a case of the boil of Gafsa. Caducee 1905; 10:1-2. 
Ouzennou N, Boussaa S, Ben Alla S, Boumezzough A. Observational study to assess pregnant women's knowledge and behaviour related to toxoplasmosis in Essaouira province, Morocco. Asian Pac J Trop Med 2019; 12:87-90.

Reda WW, Mostafa O. Epidemiological studies on ocular catscratch-disease. Vet Med J Giz 1995; 43:383-388.

Rifaat MA, Arafa MS, Sadek MS, Nasr NT, et al. Toxoplasma infection of stray cats in Egypt. J Trop Med Hyg 1976; 79: 67-70.

Rifaat MA, Morsy TA, Sadek MS, Mahmoud AM. Antibodies against some parasites in stray cats in Cairo. J Egypt Soc Parasitol 1981; 11:517-524.

Romia SA, Makhlouf LM, el-Malky SA, Handoussa AE, et al. Seroepidemiologic observations on human toxoplasmosis in Dakahlia Governorate. J Egypt Soc Parasitol 1988; 18:493.

Rouatbi M, Amairia S, Amdouni Y, Boussaadoun MA, et al. Toxoplasma gondii infection and toxoplasmosis in North Africa: A review. Parasite 2019; 26:6.

Salem M, El-Deeb W, Abdel-Moein K, El-Sayed A, et al. Detection of Mycobacterium avium subsp. paratuberculosis in an Egyptian mixed breeding farm and comparative molecular characterisation of isolates from cattle, camels, and cats a case report. Bulg J Vet Med 2019; 22:41-49.

Sallem RB, Gharsa H, Slama KB, Rojo-Bezares B, et al. First detection of CTX-M-1, CMY-2, and QnrB19 resistance mechanisms in fecal Escherichia coli isolates from healthy pets in Tunisia. Vector Borne Zoonotic Dis 2013; 13:98-102.

Salyer SJ, Silver R, Simone K, Barton Behravesh C. Prioritizing zoonoses for global health capacity building-themes from one health zoonotic disease workshops in 7 countries, 2014-2016. Emerg Infect Dis 2017; 23:S55-S64.

Sbai MA, Dabloun S, Benzarti S, Khechimi M, et al. Acute carpal tunnel syndrome of the hand following a cat bite. Pan Afr Med J 2015; 21:206.

Siam MA, Karim AA, Hamed OM, Zakaria A. The possible role of stray dogs and cats in the epidemiology of some bacterial human pathogens in Egypt. Zentralbl Veterinarmed B 1973; 20:409-414.

Stoszek SK, Abdel-Hamid M, Saleh DA, Kafrawy SE, et al. High prevalence of hepatitis E antibodies in pregnant Egyptian women. Trans R Soc Trop Med Hyg 2006; 100:95-101.

Torgerson PR, Macpherson CNL. The socioeconomic burden of parasitic zoonoses: Global trends. Vet Parasitol 2011; 182: 79-95.

Tuzio H, Edwards D, Elston T, Jarboe L, et al. Feline zoonoses guidelines from the American association of feline practitioners. J Feline Med Surg 2005; 7:243-274.

Vitale KR, Behnke AC, Udell MA. Attachment bonds between domestic cats and humans. Curr Biol 2019; 29:R864-R865.

Veterinarians and Veterinary Para-Professionals. WAHIS Interface from World Organisation for Animal Health (OIE).
2018. Available at https://oie.int/wahis_2/public/wahid.php/ Countryinformation/Veterinarians

Waly N, Kamel R, Ahmed L, Ismail M. Prevalence of dermatophytosis in dogs and cats in Egypt. In BSAVA Congress Proceedings 2017, Birmingham, UK, BSAVA Library 2017: 457.

Wareth G, Melzer F, El-Diasty M, Schmoock G, et al. Isolation of Brucella abortus from a dog and a cat confirms their biological role in re-emergence and dissemination of bovine brucellosis on dairy farms. Transbound Emerg Dis 2017; 64:e27-e30.

World Bank. Middle East and North Africa. 2019. Available at https://worldbank.org/en/region/mena

World Health Organization. Summary of global update on preventative chemotherapy implementation in 2015. Weekly Epidemiol Rec 2016; 91:456-460.

World Health Organization. United against rabies collaboration, first annual progress report: Global strategic plan to end human deaths from dog-mediated rabies by 2030. WHO, FAO, and OIE, Geneva, Switzerland. 2019. Available at https:// apps.who.int/iris/rest/bitstreams/1251282/retrieve

Younis K, Baddour M, Ibrahim MS. Detection of diarrheagenic Escherichia coli in pet animals and its antibiotic resistance in Alexandria Governorate. Alex J Vet Sci 2015; 45.

Yousef Y, Atia M, Esmaell A. Dermatophytes in animals, birds and man. 1. Animals as a potential reservoir of dermatophytes to man. Assiut Ved Med J 1977; 4:151.

Yousfi M, Mairi A, Touati A, Hassissene L, et al. Extended spectrum $\beta$-lactamase and plasmid mediated quinolone resistance in Escherichia coli fecal isolates from healthy companion animals in Algeria. J Infect Chemother 2016; 22:431-435.

Yousfi M, Touati A, Mairi A, Brasme L, et al. Emergence of carbapenemase-producing Escherichia coli isolated from companion animals in Algeria. Microb Drug Resist 2016; 22:342-346.

Zim A. Helminths of dogs and cats in Egypt. Ann Parasitol Hum Comp 1939; 17:32-36.

Zouari S, Khrouf F, M'ghirbi Y, Bouattour A. First molecular detection and characterization of zoonotic Bartonella species in fleas infesting domestic animals in Tunisia. Parasit Vectors 2017; 10:436.

Address correspondence to: Amber N. Barnes Department of Public Health University of North Florida Building 39, Room 3011 1 UNF Drive Jacksonville, FL 32224

USA

E-mail: amber.barnes@unf.edu 